The utility of the Edinburgh Depression Scale as a screening tool for depression in Parkinson's disease

Running head: Validity of the Edinburgh Depression Scale in PD

Keywords: Parkinson's disease, depression, Edinburgh Depression Scale, validity

Key points:

1. Depression is common in people with PD, and is frequently missed or untreated.

2. Routine screening in outpatient clinics could improve identification of patients with significant depressive symptoms.

3. The Edinburgh Depression Scale is a valid and potentially useful screening instrument for patients who have PD.

Authors: Sarah Baillon ${ }^{1}{ }^{*}$, James Lindesay ${ }^{1}$, Pravin Prabhakaran ${ }^{2}$, Oli Hands ${ }^{3}$, Jonathan Murray ${ }^{3}$, Suzanne Stacey ${ }^{3}$, Sandhya Gaur ${ }^{3}$, Aniruddha Rajkonwar ${ }^{4}$, Jayaraj Padmanabhan ${ }^{3}$, Deepak Shukla ${ }^{3}$ Santanu Chakrabarti ${ }^{3}$, Nelson Lo ${ }^{5}$ and Michael Dennis ${ }^{6}$

${ }^{1}$ Department of Health Sciences, University of Leicester, Leicester, UK

${ }^{2}$ Worcestershire Health and Care NHS Trust, Worcester, UK

${ }^{3}$ Leicestershire Partnership NHS Trust, Leicester, UK

${ }^{4}$ Tees, Esk and Wear Valley NHS Trust, County Durham, UK

${ }^{5}$ Department of Geriatric Medicine, University Hospitals of Leicester NHS Trust, Leicester, UK

${ }^{6}$ College of Medicine, Swansea University, Wales, UK

* Corresponding Author: Dr Sarah Baillon (PhD), Research Fellow, Psychiatry for the Elderly, Department of Health Sciences, University of Leicester, 22-28 Princess Road West, Leicester, UK, LE1 6TP, E-mail : sfb5@leicester.ac.uk, Tel. 0116 2588161, Fax. 01162584078 
Address where research was carried out: Department of Health Sciences, University of Leicester, Leicester General Hospital, Gwendolen Road, Leicester, LE5 4PW

Word count: 3,021 words

This research was not supported by any specific funding. 


\section{THE UTILITY OF THE EDINBURGH DEPRESSION SCALE AS A SCREENING TOOL FOR DEPRESSION IN PARKINSON'S DISEASE}

\section{ABSTRACT}

Objective: This study aimed to evaluate the Edinburgh Depression Scale (EDS) as a screening tool for use in a Parkinson's disease (PD) population. Many commonly-used depression scales include items relating to somatic symptoms that also occur in PD which could potentially result in inaccurate reporting of depressive symptoms. The EDS is a scale which incorporates no somatic items.

Method: 120 patients attending specialist PD clinics were assessed using a standardized diagnostic interview (PSE-SCAN) to establish a diagnosis of DSM-IV depression. They later completed the EDS with another researcher who was blind to the results of diagnostic interview. A receiver operating characteristics curve analysis was carried out to identify the optimal threshold score on the EDS, and the Brief EDS, to identify any depressive disorder, or major depression. The performance characteristics at a range of thresholds were compared.

Results: A cut-off score of $10 / 11$ gave maximal discriminant validity, with $74 \%$ sensitivity, 92\% specificity and $64 \%$ positive predictive value for the identification of any depression according to DSM-IV criteria.

Conclusions: This study suggests the EDS is both a valid and potentially useful instrument which can be used as a quick self-completion questionnaire for screening for depression in people who have PD.

Declaration of interest: None Keywords: Parkinson's disease, depression, Edinburgh Depression Scale, validity 


\section{INTRODUCTION}

Depression is commonly associated with Parkinson's disease - it is estimated that up to 50\% of people who have PD are affected by depression (Reijnders, et al. 2008) although these estimates vary according to the sample studied, the assessment methods used and the diagnostic criteria applied. Importantly, depression has been shown to be associated with greater motor and cognitive decline (Cubo, et al. 2000), deterioration of functional ability (Weintraub, et al. 2004) and reduced quality of life (The Global Parkinson's Disease Survey (GPDS) Steering Committee 2002).

The diagnosis of depression in PD is not straightforward and is complicated by the fact that many of the somatic symptoms of depression are also symptoms that occur in PD. This means that it is difficult for clinicians to identify when a depressive illness is present - for example, complaints of fatigue, impaired concentration and insomnia could be attributed to PD and consequentially depression may be under-recognised and under-treated in PD (Weintraub, et al. 2003). In the United Kingdom (UK) current clinical practice guidelines for depression produced by the National Institute for Health and Clinical Excellence (NICE) recommend screening in patient groups at high risk of depressive illness (National Institute for Health and Clinical Excellence 2004) and it is possible that routine screening in patients with PD would improve the identification of patients with depression.

The choice of an appropriate screening measure in PD is not simple. Due to the overlap of many of the somatic symptoms of depression with the symptoms of PD the usefulness of commonly used depression scales in PD may be compromised. Therefore a depression scale which has few or no items relating to somatic symptoms of depression should have greater 
utility when used in this patient group. The Edinburgh Depression Scale (EDS) was originally developed and validated to identify depression in women during the post-natal period (Cox, et al. 1987). The scale has no items relating to somatic symptoms of depression and instead relies upon identifying cognitive-affective symptoms. It is a 10-item scale designed for selfcompletion by the patient (each item scores $0-3$, with a higher score indicating more depressive symptoms). The scale has been validated in studies of non-postnatal women (Gibson, et al. 2009) and in palliative care (Lloyd-Williams, et al. 2004; Lloyd-Williams, et al. 2000) and would seem well-suited for use in a PD patient population. A shorter, 6-item version of the EDS has also been validated in palliative care, the Brief Edinburgh Depression Scale (BEDS) (Lloyd-Williams, et al. 2007). The aim of this study was therefore to explore the utility and validity of the EDS and the BEDS in an outpatient PD sample.

\section{METHODS}

This study was part of a project already described (Baillon, et al. 2013) and was approved by the local Research Ethics Committee. Participants were either newly diagnosed or on-going patients attending the PD clinics at Leicester General Hospital, UK. All participants had a diagnosis of PD according to diagnostic criteria defined by the UK Parkinson's Disease Society Brain Bank (de Rijk, et al. 1997), were English-speaking and able to give informed consent to take part in the research. Participants received two visits at their home for the purposes of the study. At the first visit they completed section 21 of the Present State Examination - Schedules for Clinical Assessment in Neuropsychiatry (SCAN) (World Health Organisation 1999) which incorporates the Mini-Mental State Examination (Folstein, et al. 1975). Those who scored less than 24 on the MMSE were excluded from the remainder of the study; this cut-off was chosen as this is the most widely used in research to exclude 
patients with dementia, with sensitivity of $87 \%$ and PPV of $79 \%$ (Folstein, et al. 2001; Lopez, et al. 2005; Tombaugh and McIntyre 1992). Next, the sections of the SCAN interview pertaining to depression (sections 6, 7 and 8) were completed with the participant. A DSMIV diagnosis (American Psychiatric Association 1994) of major, minor or no depression was derived from this standardised interview and established the gold standard in this study. The diagnosis of major depression was obtained by running the diagnostic algorithm of the SCAN software. The diagnosis of minor depression was derived from the responses to the items of the SCAN interview and adhering to the DSM-IV criteria for minor depression.

The participant was visited by another researcher within five days of the initial SCAN assessment and completed the EDS. This second researcher was blind to the outcome of the SCAN interview. Participants were given the choice of completing the questionnaire themselves, reading the items and indicating their response verbally or having the items and responses read to them verbatim. The length of time since diagnosis of PD and the severity of PD at the time the study, as indicated by the Hoehn and Yahr stage (Hoehn and Yahr 1967) were retrieved from the participant's clinic notes.

The sensitivity (Se), specificity (Sp), positive and negative predictive values (PPV and NPV) were calculated at various different cut-off points for the EDS to identify the optimal threshold scores for patients with PD. A receiver operating characteristic (ROC) curve was generated in order to calculate the area under the curve (AUC), and the positive and negative likelihood ratios (PLR and NLR) and diagnostic odds ratio (DOR) were calculated. These test characteristics were calculated for the identification of those participants with either major or minor depression, and for the identification of those with major depression. 
Data were analysed using the Statistical Package for the Social Sciences version 18.0. Nonparametric methods were used throughout as the data was not normally distributed.

\section{RESULTS}

A total of 136 patients participated in the study but 15 were excluded due to likely cognitive impairment (i.e. MMSE score less than 24) and one declined to continue in the study following the SCAN interview. The characteristics of the remaining 120 participants are shown in Table 1. Hoehn and Yahr ratings were only available for 59 (50\%) participants, of which 55 (93\%) were Hoehn and Yahr Stage 1-2 (minimal disability). Nineteen (15.8\%) participants met DSM-IV criteria for a depressive disorder - $14(11.7 \%)$ had a diagnosis of major depression, 5 (4.2\%) of minor depression and none received a diagnosis of dysthymia. Participants who were identified as depressed were not significantly different in terms of gender (Pearson $\chi^{2}$ (two-tailed)=1.7, $\left.d f=1, P=0.19\right)$, age (Mann-Whitney $U$ test, NS), length of time since diagnosis of PD (Mann-Whitney U test, NS) nor MMSE score (Mann-Whitney U test, NS) but had significantly higher EDS (Mann-Whitney $U$ test, $\mathrm{P}<0.001$ ) and BEDS (MannWhitney $\mathrm{U}$ test, $\mathrm{P}<0.001)$ scores.

\section{Identification of minor and major depression}

Table 2 summarises the performance characteristics of the EDS when different threshold scores are used to identify cases with minor or major depression according to DSM-IV criteria. The optimal cut-off for the scale in this sample was taken to be that which maximises the sensitivity and specificity of the scale. In this instance the optimal cut-off is 10/11 which correctly identified 14/19 (74\%) participants who were diagnosed with depression (11/14 of those with major depression), and incorrectly identified 8/101 (8\%) 
non-depressed participants. Often, when using a scale to screen for a condition, a different cut-off score is used in order to optimise the sensitivity and the NPV. The threshold score of 8/9 gave a better combination of these characteristics. At this cut-off $15 / 19$ (79\%) of depressed patients were identified. Figure 1 shows the ROC curve for the EDS identification of DSM-IV minor or major depression. The area under the curve was $0.904(p<0.001,95 \%$ confidence interval $0.834-0.974)$.

Table 3 summarises the performance of the BEDS across a range of thresholds. The optimal cut-off for the scale in this sample is $4 / 5$ which correctly identified $17 / 19$ (90\%) participants who were diagnosed with depression (13/14 of those with major depression), but incorrectly identified 32/101 (32\%) non-depressed participants. The area under the curve for the BEDS, calculated from the ROC curve analysis, was $0.882(p<0.001,95 \%$ confidence interval 0.808 - 0.956). See Figure 1.

\section{Identification of major depression}

As for the identification of 'any depression' the optimal cut-off on the EDS for the identification of DSM-IV major depression was found to be 10/11 (see Table 4). Although a lower cut-off gives higher specificity it is at the cost of poor specificity - the 10/11 cut-off appears to give a better balance. At this cut-off $11 / 14$ (79\%) cases of major depression were correctly identified and 11/106 (10\%) of non-depressed participants were incorrectly identified as cases. The threshold that gave the optimal combination of sensitivity and NPV (whilst maintaining reasonable specificity) was $8 / 9$, which identified $12 / 14$ (86\%) of patients diagnosed with major depression. The AUC for the EDS identification of DSM-IV major depression was 0.888 ( $p<0.001,95 \%$ confidence interval 0.805-0.972). 
Table 5 shows the test characteristics of the BEDS for the identification of those participants diagnosed with major depression. The optimal cut-off for the identification of major depression was $4 / 5$. At this cut-off $13 / 14$ (93\%) cases of major depression were correctly identified and 36/106 (34\%) of non-depressed participants were incorrectly identified as cases. The AUC for the BEDS identification of DSM-IV major depression was 0.857 ( $p<0.001$, 95\% confidence interval 0.768-0.945).

\section{DISCUSSION}

This study was designed to investigate the validity and utility of the EDS as a depression screening measure in patients with PD. The hypothesis was that the EDS, as a scale with no items that relate to the somatic symptoms of depression, would have superior performance in a PD sample to other commonly used depression screening scales. In this study of PD outpatients, the cut-off that represented the optimal combination of sensitivity and specificity on the EDS was $10 / 11$ and had sensitivity of $74 \%$, specificity of $92 \%$ and PPV of $64 \%$ for the identification of any depression (minor and major depression), and sensitivity of $79 \%$, specificity of $90 \%$ and PPV of $50 \%$ for the identification of those with major depression. The shorter version of the scale, the BEDS, showed sensitivity of $89 \%$, specificity of $68 \%$ and much lower PPV of $35 \%$ (and therefore a higher rate of misclassification). In practice a higher or lower threshold may be preferable, depending upon the relative importance of minimising false positives or false negatives.

The performance characteristics of the EDS are comparable to but not significantly better than those of other depression scales that have been validated in PD. A review of 
depression scales was carried out by a group of experts in PD and the authors suggested that self-report scales are more practical for routine clinical screening than clinician-rated scales, despite slightly poorer performance characteristics (Schrag, et al. 2007). Of the selfreport scales considered in the review, the Beck Depression Inventory (BDI), the Hospital Anxiety and Depression Scale (HADS) and the Geriatric Depression Scale (GDS) (both the 30 and 15 -item versions) were felt to be the most useful for screening for depression. Since that review, a recent study has evaluated and compared the performance of several different depression scales in PD (Williams, et al. 2012). The study demonstrated comparable results with previous studies of the scales and the authors felt the GDS-30 to be the most efficient for screening (in terms of psychometric properties and use of clinician time) with a sensitivity of $72 \%$, specificity of $82 \%$ (PPV 73\%, NPV $81 \%$, and AUC 0.83). Although not reported in this paper, the participants in the current study completed the GDS-15 in addition to the EDS (Baillon et al. 2013). The GDS-15 was shown to have similarly strong performance characteristics (sensitivity $84 \%$, specificity $89 \%$, PPV 59\%, NPV $97 \%$ and AUC 0.92) as those demonstrated in the study by Williams et al. (Williams et al. 2012).

The performance of the EDS in terms of identification of minor or major depression appears to be as good as many other self-report measures (Williams et al. 2012) provided the PDspecific cut-off score is used, but the fact that the scale has no items relating to the somatic symptoms of depression does not seem to give it superior performance. It is a short selfreport questionnaire and as such would be more suitable for routine clinical screening than longer scales (such as the BDI or GDS-30) or those which require completion by a trained member of staff and it may have the advantage of greater face validity (with both patients and clinicians) due to the absence of items relating to symptoms that also occur in PD. 
Additionally, there is an item relating to self-harm that should alert the clinician to enquire further and seek appropriate advice about management if necessary; older people with physical ill-health, disability, and depression are of particular high risk of suicide (Dennis 2009).

The optimal cut-off on the EDS identified in this study for screening for any depressive disorder is higher than the recommended cut-off of $9 / 10$ reported in studies of different patient groups (post-natal women (Cox, et al. 1996); palliative care patients (Lloyd-Williams et al. 2004)) which illustrates the importance of validating a scale in a new patient group rather than applying the cut-off identified in another sample. In this study the participants were given the option to respond to the items verbally rather than completing the questionnaire, which many chose to do because of problems with tremors and handwriting. It is not known how this could have impacted upon the results. Research into oral versus written presentation of a depression scale has suggested that respondents report less depressive responses when answering orally (Cannon, et al. 2002), so it is possible that it may have resulted in lower scores on the EDS and thereby a higher optimum cut-off for identifying clinically important depression.

Some might question the use of DSM-IV criteria for depression as the gold standard in this study due to the problems associated with the attribution of somatic symptoms to PD. However, there is no better standardised criterion available (other standardised criteria also include somatic symptoms) and if the results of this study are to be comparable with studies reporting the performance of other screening measures it is best to use the most widely used gold standard. The SCAN diagnostic algorithm for DSM-IV major depression enables 
the clinician to indicate when they feel there should be clear attribution of a somatic symptom to PD - otherwise an inclusive approach is taken (as recommended by Marsh et al. (Marsh, et al. 2006)).

The $16 \%$ prevalence of depression was lower than reported in many similar studies of depression scales in PD, and is significantly lower than the mean prevalence in out-patient samples reported in the review of prevalence studies carried out by Reijnders et al (2008). In our study $22(18 \%)$ participants were prescribed anti-depressant medication, suggesting a high prevalence of treated depression although 8 still met depression criteria. Out of those identified as depressed $58 \%$ were not prescribed an antidepressant illustrating the potential importance of screening.

It is important to note that the sample studied here had predominantly mild to moderate PD and therefore results cannot be generalised to patients with more severe PD. However, it is important to validate a screening measure in the type of population in which the screening would take place and this sample was typical of a PD outpatient clinic where the majority of patients are in the mild to moderate stages of the disease. The study also excluded patients who performed less well on cognitive testing and so the results cannot be generalised to patients who have dementia in PD. As a significant proportion (up to $80 \%$ ) of people with PD will experience cognitive impairment to some degree (Aarsland, et al. 2003) it is important that consideration is given to whether a depression screening measure is effective in such patients. The Cornell Scale for Depression in Dementia (Alexopoulos, et al. $1988 \mathrm{a}, \mathrm{b})$ has been shown to be effective in PD for patients with and without dementia, but as a clinician-rated scale it is not as practical for routine clinical screening. 
This study shows that the EDS could be used in clinical practice to screen for depression in an outpatient PD clinic, provided an appropriate cut-off score is used. Whilst no substitute for thorough clinical diagnostic assessment, use of such a measure can highlight those patients who may warrant further investigation regarding their mood. It is important that screening for depression should take place in a clinical environment that can provide adequate collaborative care management of those patients identified as having significant depressive symptoms in order to ensure improved clinical outcomes - without this screening for the condition is of limited value.

Although there is significant support for the use of antidepressant medications from both open-label trials and clinical practice, until recently the benefit remained to be established in rigorous randomised controlled trials for each of the categories of antidepressant medication available (Ghazi-Noori, et al. 2003; National Institute for Health and Clinical Excellence 2006). However, a recent review of treatments for depression in PD carried out by the Movement Disorder Society concluded that some treatments are efficacious and others likely to be, which suggests that good quality evidence of treatment benefit for PD patients is mounting (Seppi, et al. 2011).

Although the EDS performed well the published literature suggests that other measures, in particular the GDS (either the 30 or 15 -item version) may have equally good sensitivity and specificity but better PPV (which would mean fewer false-positives) (Schrag et al. 2007; Williams et al. 2012). However, the EDS is a short self-report questionnaire that does not require trained staff to complete, and does not have potentially confounding items relating 
to somatic symptoms that also occur in PD. Further research validating the measure in a more clinically diverse sample of PD patients would enable further assessment of the utility of a scale in such patients. The EDS also has the benefit of being validated across the age spectrum in different general hospital patient groups (postnatal women (Cox et al. 1996), menopausal women (Becht, et al. 2001), palliative care (Lloyd-Williams et al. 2000; LloydWilliams et al. 2007). If one instrument is valid and used routinely in multiple health settings within the general hospital clinicians will gain familiarity and confidence in its use, which should improve the identification of depression in patients throughout the hospital setting. 


\section{REFERENCES}

Aarsland D, Anderson K, Larsen JP, Lolk A. 2003. Prevalence and characteristics of dementia in Parkinson's disease: an 8-year prospective study. Archives of Neurology 60 : 387-392.

Alexopoulos G, Abrams R, Young R, Shamoian C. 1988a. Cornell Scale for depression in dementia. Biological Psychiatry 23: 271-284.

Alexopoulos G, Abrams R, Young R, Shamoian C. 1988b. Use of the Cornell scale in nondemented patients. Journal of the American Geriatrics Society 36 : 230-236.

American Psychiatric Association. 1994. Diagnostic and Statistical Manual of Mental Disorders. Fourth Edition. Washington, DC: American Psychiatric Association.

Baillon S, Dennis MS, Lo N, Lindesay J. 2013. Screening for depression in Parkinson's disease: The performance of two screening questions, Age and Ageing 43 : 200-205. DOI: 10.1093/ageing/aft152

Becht M, van Erp C, Teeuwisse T, van Heck G, van Son M, Pop V. 2001. Measuring depression in women around menopausal age. Towards a validation of the Edinburgh Depression Scale. Journal of Affective Disorders 63 : 209-213.

Cannon BJ, Thaler T, Roos S. 2002. Oral versus written administration of the Geriatric Depression Scale. Aging and Mental Health 6 : 418-422.

Cox JL, Chapman G, Murray D, Jones P. 1996. Validation of the Edinburgh postnatal depression scale (EPDS) in non-postnatal women. Journal of Affective Disorders 39 : 185189. 
Cox JL, Holden JM, Sagovsky R. 1987. Detection of postnatal depression. Development of the 10-item Edinburgh Postnatal Depression Scale. British Journal of Psychiatry 150 : 782-786.

Cubo E, Bernard B, Leurgans S, Raman R. 2000. Cognitive and motor function in patients with Parkinson's disease with and without depression. Clinical Neuropharmacology 23 : 331 334.

de Rijk M, Rocca W, Anderson D, Melcon M, Breteler M, Maraganore D. 1997. A population perspective on diagnostic criteria for Parkinson's disease. Neurology 48 : 1277-1281.

Dennis MS. 2009. Suicide and self-harm in older people. Quality in Ageing 10 : 16-23.

Folstein M, Folstein S, McHugh P. 1975. Mini-mental State - a practical method for grading the cognitive state of patients for the clinician. Journal of Psychiatric Research 12 : 189-198.

Folstein M, Folstein S, McHugh P, Fanjiang G. 2001. Mini-Mental State Examination user's guide. Florida: Odessa.

Ghazi-Noori S, Chung TH, Deane K, Rickards H, Clarke CE. 2003. Therapies for depression in Parkinson's disease (Review). Cochrane Database of Systematic Reviews Art No. CD003465. DOI: 003410.001002/14651858.CD14003465.

Gibson J, McKenzie-McHarg K, Shakespeare J, Price J, Gray R. 2009. A systematic review of studies validating the Edinburgh postnatal depression Scale in antepartum and postpartum women. Acta Psychiatrica Scandinavica 119 : 350-364. DOI: 10.1111/j.16000447.2009.01363.x

Hoehn MM, Yahr MD. 1967. Parkinsonism: onset, progression and mortality. Neurology 17 : 427-442. 
Lloyd-Williams M, Dennis MS, Taylor F. 2004. A prospective study to compare three depression screening tools in patients who are terminally ill. General Hospital Psychiatry 26 : 384-389. DOI: 10.1016/j.genhosppsych.2004.04.002

Lloyd-Williams M, Friedman T, Rudd N. 2000. Criterion validation of the Edinburgh postnatal depression scale as a screening tool for depression in patients with advanced metastatic cancer. Journal of Pain and Symptom Management 20 : 259-265.

Lloyd-Williams M, Sheils D, Dowrick C. 2007. The development of the Brief Edinburgh Depression Scale (BEDS) to screen for depression in patients with advanced cancer. Journal of Affective Disorders 99 : 259-264. DOI: 10.1016/j.jad.2006.09.015

Lopez M, Charter R, Mostafavi B, Nibut L, Smith W. 2005. Psychometric properties of the Folstein Mini-Mental State Examination. Assessment 12 : 137-144.

Marsh L, McDonald WM, Cummings JL, Ravina B, the NINDS/NIMH Work Group on Depression and Parkinson's Disease. 2006. Provisional diagnostic criteria for depression in Parkinson's disease: Report of a NINDS/NIMH Work Group. Movement Disorders 21 : 148158. DOI: $10.1002 / m d s .20723$

National Institute for Health and Clinical Excellence. 2004. Depression. Management of depression in primary and secondary care. Clinical Guideline 23. London: National Institute for Clinical Excellence.

National Institute for Health and Clinical Excellence. 2006. Parkinson's disease. National clinical guideline for diagnosis and management in primary and secondary care. Clinical Guideline 35. London: National Institute for Health and Clinical Excellence. 
Reijnders J, Ehrt U, Weber W, Aasland D, Leentjens A. 2008. A systematic review of prevalence studies of depression in Parkinson's disease. Movement Disorders 23 : 183-189. DOI: $10.1002 / \mathrm{mds} .21803$

Schrag A, Barone P, Brown RG, Leentjens AFG, McDonald WM, Starkstein SE, Weintraub D, Poewe W, Rascol O, Sampaio C, et al. 2007. Depression Rating Scales in Parkinson's disease: critique and recommendations. Movement Disorders 22 : 1077-1092. DOI: $10.1002 / \mathrm{mds} .21333$

Seppi K, Weintraub D, Coelho M, Perez-Lloret S, Fox SH, Katzenschlager R, Hametner E-M, Poewe W, Rascol O, Goetz CG, et al. 2011. The Movement Disorder Society Evidence-Based Medicine Review Update: Treatments for the non-motor symtpoms of Parkinson's disease. Movement Disorders 26 : S42-S80. DOI: 10.1002/mds.23884

The Global Parkinson's Disease Survey (GPDS) Steering Committee. 2002. Factors impacting on Quality of life in Parkinson's disease: Results from an international survey. Movement Disorders 17 : 60-67. DOI: 10.1002/mds.10010

Tombaugh T, Mclntyre N. 1992. The mini-mental state examination: a comprehensive review. Journal of the American Geriatrics Society 40 : 922-935.

Weintraub D, Moberg PJ, Duda JE, Katz IR, Stern MB. 2003. Recognition and treatment of depression in Parkinson's disease. Journal of Geriatric Psychiatry and Neurology 16 : 178183. DOI: $10.1177 / 0891988703256053$ 
Weintraub D, Moberg PJ, Duda JE, Katz IR, Stern MB. 2004. Effect of psychiatric and other nonmotor symptoms on disability in Parkinson's disease. Journal of the American Geriatrics Society 52 : 784-788.

Williams JR, Hirsch ES, Anderson K, Bush AL, Goldstein SR, Grill S, Lehmann S, Little JT, Margolis RL, Palanci J, et al. 2012. A comparison of nine scales to detect depression in Parkinson's disease. Neurology 78 : 998-1006.

World Health Organisation. 1999. Schedules for Clinical Assessment in Neuropsychiatry Interview. Version 2.1. Geneva: World Health Organisation. 
Figure 1-ROC curve for EDS and BEDS identification of DSM-IV minor and major depression showing the performance at the main cut-off scores for each scale

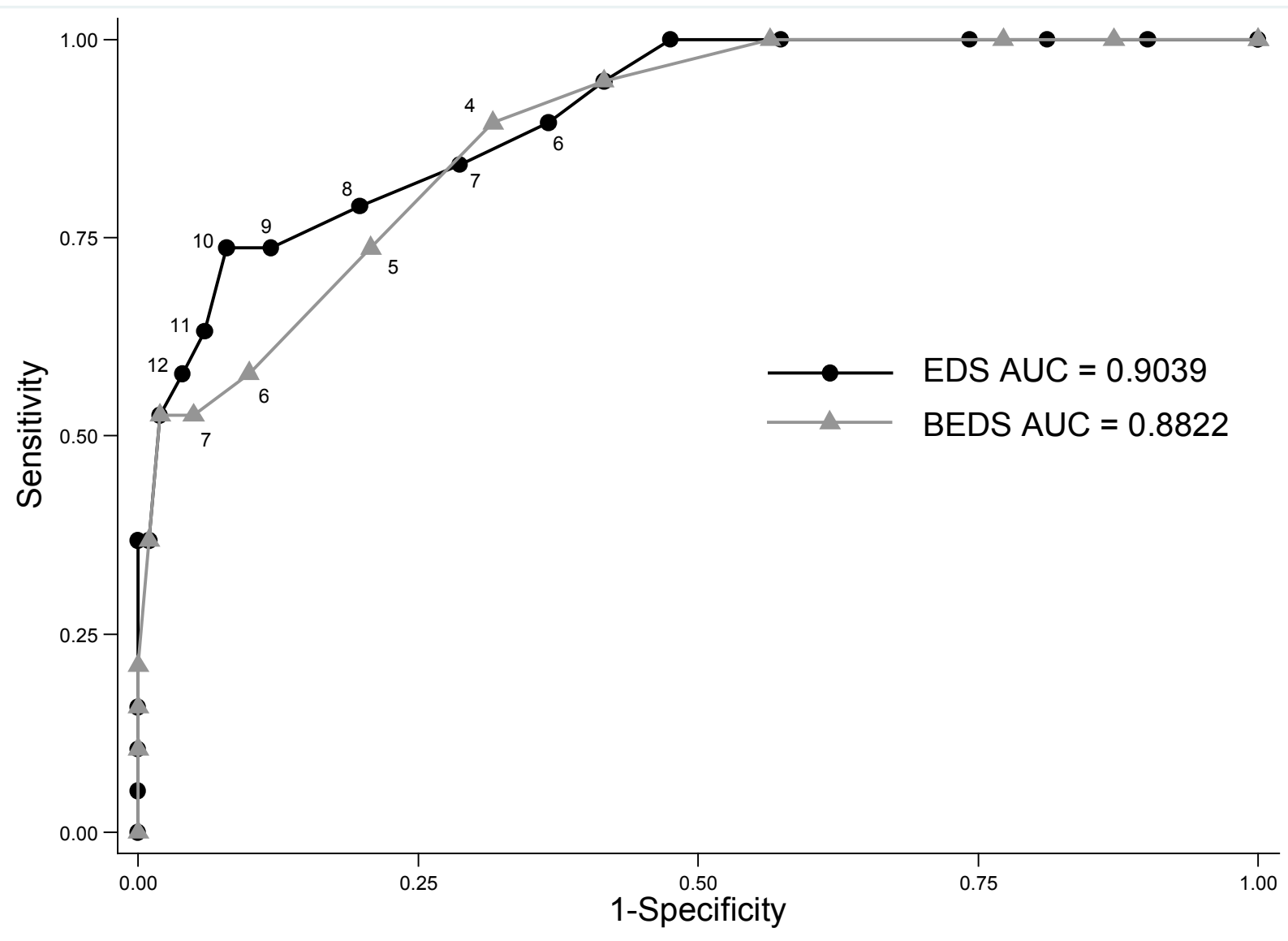




\begin{tabular}{|c|c|c|c|c|}
\hline & & $\begin{array}{l}\text { Whole } \\
\text { sample } \\
\mathrm{N}=120\end{array}$ & $\begin{array}{r}\text { Non- } \\
\text { depressed } \\
\mathrm{N}=101\end{array}$ & $\begin{array}{r}\text { Depressed* }^{*} \\
\qquad N=19\end{array}$ \\
\hline \multirow[t]{2}{*}{ Gender } & Male & 67 (55.1\%) & 59 (58.4\%) & $8(42.1 \%)$ \\
\hline & Female & 53 (44.9\%) & 42 (41.6\%) & 11 (57.9\%) \\
\hline Age (years) & Median (IQR) & $74.0(13.8))$ & $74.0(13.0)$ & $74.0(16.0)$ \\
\hline $\begin{array}{l}\text { Time since diagnosis } \\
\text { of PD (months) }\end{array}$ & Median (IQR) & $25.0(67.3)$ & $25.0(67.5)$ & $25.0(69.0)$ \\
\hline MMSE Score & Median (IQR) & $28.0(2.0)$ & $28.0(2.0)$ & $27.0(3.0)$ \\
\hline $\begin{array}{l}\text { Antidepressant } \\
\text { medication }\end{array}$ & N (\% Yes) & $22(18.3 \%)$ & $14(13.9 \%)$ & $8(42.1 \%)$ \\
\hline EDS Score & Median (IQR) & $5.5(6.0)$ & $4.0(6.0)$ & $14.0(7.0)$ \\
\hline BEDS Score & Median (IQR) & $3.5(4.0)$ & $3.0(3.0)$ & $9.0(5.0)$ \\
\hline
\end{tabular}

* all participants classified as having major or minor depression on SCAN 
Table 2 - Test characteristics of EDS for identification of minor or major depression (DSMIV)

\begin{tabular}{|c|c|c|c|c|c|c|c|c|}
\hline $\begin{array}{l}\text { Cut- } \\
\text { off }\end{array}$ & $\begin{array}{c}\text { Se } \\
(95 \% \mathrm{Cl})\end{array}$ & $\begin{array}{c}\text { Sp } \\
(95 \% \mathrm{Cl})\end{array}$ & $\begin{array}{c}\text { PPV } \\
(95 \% \mathrm{Cl})\end{array}$ & $\begin{array}{c}\text { NPV } \\
(95 \% \mathrm{Cl})\end{array}$ & PLR & NLR & DOR & OMR \\
\hline $6 / 7$ & $\begin{array}{c}0.89 \\
(0.69-0.97)\end{array}$ & $\begin{array}{c}0.63 \\
(0.54-0.72)\end{array}$ & $\begin{array}{c}0.31 \\
(0.21-0.45)\end{array}$ & $\begin{array}{c}0.97 \\
(0.90-0.99)\end{array}$ & 2.44 & 0.17 & 14.70 & 0.33 \\
\hline $7 / 8$ & $\begin{array}{c}0.84 \\
(0.62-0.95)\end{array}$ & $\begin{array}{c}0.71 \\
(0.62-0.79)\end{array}$ & $\begin{array}{c}0.36 \\
(0.23-0.50)\end{array}$ & $\begin{array}{c}0.96 \\
(0.89-0.99)\end{array}$ & 2.93 & 0.22 & 13.24 & 0.27 \\
\hline $8 / 9$ & $\begin{array}{c}0.79 \\
(0.57-0.92)\end{array}$ & $\begin{array}{c}0.80 \\
(0.71-0.87)\end{array}$ & $\begin{array}{c}0.43 \\
(0.28-0.59)\end{array}$ & $\begin{array}{c}0.95 \\
(0.89-0.98)\end{array}$ & 3.99 & 0.26 & 15.19 & 0.20 \\
\hline 9/10 & $\begin{array}{c}0.74 \\
(0.51-0.88)\end{array}$ & $\begin{array}{c}0.88 \\
(0.80-0.93)\end{array}$ & $\begin{array}{c}0.54 \\
(0.36-0.71)\end{array}$ & $\begin{array}{c}0.95 \\
(0.88-0.98)\end{array}$ & 6.20 & 0.30 & 20.77 & 0.14 \\
\hline $10 / 11^{a}$ & $\begin{array}{c}0.74 \\
(0.51-0.88)\end{array}$ & $\begin{array}{c}0.92 \\
(0.85-0.96)\end{array}$ & $\begin{array}{c}0.64 \\
(0.43-0.80)\end{array}$ & $\begin{array}{c}0.95 \\
(0.89-0.98)\end{array}$ & 9.30 & 0.29 & 32.55 & 0.11 \\
\hline $11 / 12$ & $\begin{array}{c}0.63 \\
(0.41-0.81)\end{array}$ & $\begin{array}{c}0.94 \\
(0.88-0.97)\end{array}$ & $\begin{array}{c}0.67 \\
(0.44-0.84)\end{array}$ & $\begin{array}{c}0.93 \\
(0.87-0.97)\end{array}$ & 10.63 & 0.39 & 27.14 & 0.11 \\
\hline $12 / 13$ & $\begin{array}{c}0.58 \\
(0.36-0.77)\end{array}$ & $\begin{array}{c}0.96 \\
(0.90-0.98)\end{array}$ & $\begin{array}{c}0.73 \\
(0.48-0.89)\end{array}$ & $\begin{array}{c}0.92 \\
(0.86-0.96)\end{array}$ & 14.62 & 0.44 & 33.34 & 0.10 \\
\hline $13 / 14$ & $\begin{array}{c}0.53 \\
(0.32-0.73)\end{array}$ & $\begin{array}{c}0.98 \\
(0.93-0.99)\end{array}$ & $\begin{array}{c}0.83 \\
(0.55-0.95)\end{array}$ & $\begin{array}{c}0.92 \\
(0.85-0.96)\end{array}$ & 26.58 & 0.48 & 55.00 & 0.09 \\
\hline $14 / 15$ & $\begin{array}{c}0.37 \\
(0.19-0.59)\end{array}$ & $\begin{array}{c}0.99 \\
(0.95-1.0) \\
\end{array}$ & $\begin{array}{c}0.88 \\
(0.53-0.98)\end{array}$ & $\begin{array}{c}0.89 \\
(0.82-0.94)\end{array}$ & 37.21 & 0.64 & 58.33 & 0.11 \\
\hline
\end{tabular}


Table 3 - Test characteristics of the BEDS for identification of minor or major depression (DSM-IV)

\begin{tabular}{|c|c|c|c|c|c|c|c|c|}
\hline $\begin{array}{c}\text { Cut- } \\
\text { off }\end{array}$ & $\begin{array}{c}\text { Se } \\
(95 \% \mathrm{Cl})\end{array}$ & $\begin{array}{c}\text { Sp } \\
(95 \% \mathrm{Cl})\end{array}$ & $\begin{array}{c}\text { PPV } \\
(95 \% \mathrm{Cl})\end{array}$ & $\begin{array}{c}\text { NPV } \\
(95 \% \mathrm{Cl})\end{array}$ & PLR & NLR & DOR & OMR \\
\hline $2 / 3$ & $\begin{array}{c}1.00 \\
(0.83-1.0)\end{array}$ & $\begin{array}{c}0.44 \\
(0.34-0.53)\end{array}$ & $\begin{array}{c}0.25 \\
(0.17-0.36)\end{array}$ & $\begin{array}{c}1.00 \\
(0.92-1.0)\end{array}$ & 1.77 & 0.00 & -- & 0.48 \\
\hline $3 / 4$ & $\begin{array}{c}0.95 \\
(0.75-0.99)\end{array}$ & $\begin{array}{c}0.58 \\
(0.49-0.68)\end{array}$ & $\begin{array}{c}0.30 \\
(0.20-0.43)\end{array}$ & $\begin{array}{c}0.98 \\
(0.91-1.0)\end{array}$ & 2.28 & 0.09 & 25.29 & 0.36 \\
\hline $4 / 5^{a}$ & $\begin{array}{c}0.89 \\
(0.69-0.97)\end{array}$ & $\begin{array}{c}0.68 \\
(0.59-0.77)\end{array}$ & $\begin{array}{c}0.35 \\
(0.23-0.49)\end{array}$ & $\begin{array}{c}0.97 \\
(0.90-0.99)\end{array}$ & 2.82 & 0.15 & 18.33 & 0.28 \\
\hline $5 / 6$ & $\begin{array}{c}0.74 \\
(0.51-0.88)\end{array}$ & $\begin{array}{c}0.79 \\
(0.70-0.86)\end{array}$ & $\begin{array}{c}0.40 \\
(0.26-0.56)\end{array}$ & $\begin{array}{c}0.94 \\
(0.89-0.98)\end{array}$ & 3.54 & 0.33 & 10.67 & 0.22 \\
\hline $6 / 7$ & $\begin{array}{c}0.58 \\
(0.36-0.77)\end{array}$ & $\begin{array}{c}0.90 \\
(0.83-0.95)\end{array}$ & $\begin{array}{c}0.52 \\
(0.32-0.72)\end{array}$ & $\begin{array}{c}0.92 \\
(0.85-0.96)\end{array}$ & 5.85 & 0.47 & 12.51 & 0.15 \\
\hline $7 / 8$ & $\begin{array}{c}0.53 \\
(0.32-0.73)\end{array}$ & $\begin{array}{c}0.95 \\
(0.89-0.98)\end{array}$ & $\begin{array}{c}0.67 \\
(0.42-0.85)\end{array}$ & $\begin{array}{c}0.91 \\
(0.85-0.95)\end{array}$ & 10.63 & 0.50 & 21.33 & 0.12 \\
\hline $8 / 9$ & $\begin{array}{c}0.53 \\
(0.32-0.73)\end{array}$ & $\begin{array}{c}0.98 \\
(0.93-1.0)\end{array}$ & $\begin{array}{c}0.83 \\
(0.55-0.95)\end{array}$ & $\begin{array}{c}0.92 \\
(0.85-0.96)\end{array}$ & 26.58 & 0.48 & 55.00 & 0.09 \\
\hline
\end{tabular}


Table 4 - Test characteristics of EDS for identification of major depression (DSM-IV)

\begin{tabular}{|c|c|c|c|c|c|c|c|c|}
\hline $\begin{array}{l}\text { Cut- } \\
\text { off }\end{array}$ & $\begin{array}{c}\text { Se } \\
(95 \% \mathrm{Cl})\end{array}$ & $\begin{array}{c}\text { Sp } \\
(95 \% \mathrm{Cl})\end{array}$ & $\begin{array}{c}\text { PPV } \\
(95 \% \mathrm{Cl})\end{array}$ & $\begin{array}{c}\text { NPV } \\
(95 \% \mathrm{Cl})\end{array}$ & PLR & NLR & DOR & OMR \\
\hline $6 / 7$ & $\begin{array}{c}0.86 \\
(0.60-0.96)\end{array}$ & $\begin{array}{c}0.60 \\
(0.51-0.69)\end{array}$ & $\begin{array}{c}0.22 \\
(0.13-0.35)\end{array}$ & $\begin{array}{c}0.97 \\
(0.90-0.99)\end{array}$ & 2.16 & 0.24 & 9.14 & 0.37 \\
\hline $7 / 8$ & $\begin{array}{c}0.86 \\
(0.61-0.96)\end{array}$ & $\begin{array}{c}0.69 \\
(0.60-0.77)\end{array}$ & $\begin{array}{c}0.27 \\
(0.16-0.41)\end{array}$ & $\begin{array}{c}0.97 \\
(0.91-0.99)\end{array}$ & 2.75 & 0.21 & 13.27 & 0.29 \\
\hline $8 / 9$ & $\begin{array}{c}0.86 \\
(0.60-0.96)\end{array}$ & $\begin{array}{c}0.78 \\
(0.70-0.85)\end{array}$ & $\begin{array}{c}0.34 \\
(0.21-0.51)\end{array}$ & $\begin{array}{c}0.98 \\
(0.92-0.99)\end{array}$ & 3.95 & 0.18 & 21.65 & 0.21 \\
\hline $9 / 10$ & $\begin{array}{c}0.79 \\
(0.52-0.92)\end{array}$ & $\begin{array}{c}0.86 \\
(0.78-0.91)\end{array}$ & $\begin{array}{c}0.42 \\
(0.26-0.61)\end{array}$ & $\begin{array}{c}0.97 \\
(0.91-0.99)\end{array}$ & 5.55 & 0.25 & 22.24 & 0.15 \\
\hline $10 / 11^{a}$ & $\begin{array}{c}0.79 \\
(0.52-0.92)\end{array}$ & $\begin{array}{c}0.90 \\
(0.82-0.94)\end{array}$ & $\begin{array}{c}0.50 \\
(0.31-0.69)\end{array}$ & $\begin{array}{c}0.97 \\
(0.91-0.99)\end{array}$ & 7.57 & 0.24 & 31.67 & 0.12 \\
\hline $11 / 12$ & $\begin{array}{c}0.64 \\
(0.39-0.84)\end{array}$ & $\begin{array}{c}0.92 \\
(0.85-0.96)\end{array}$ & $\begin{array}{c}0.50 \\
(0.29-0.71)\end{array}$ & $\begin{array}{c}0.95 \\
(0.89-0.98)\end{array}$ & 7.57 & 0.39 & 19.40 & 0.12 \\
\hline $12 / 13$ & $\begin{array}{c}0.57 \\
(0.33-0.79)\end{array}$ & $\begin{array}{c}0.93 \\
(0.87-0.97)\end{array}$ & $\begin{array}{c}0.53 \\
(0.30-0.75)\end{array}$ & $\begin{array}{c}0.94 \\
(0.88-0.97)\end{array}$ & 8.65 & 0.46 & 18.86 & 0.11 \\
\hline $13 / 14$ & $\begin{array}{c}0.50 \\
(0.27-0.73)\end{array}$ & $\begin{array}{c}0.95 \\
(0.89-0.98)\end{array}$ & $\begin{array}{c}0.58 \\
(0.32-0.81)\end{array}$ & $\begin{array}{c}0.94 \\
(0.87-0.97)\end{array}$ & 10.60 & 0.52 & 20.20 & 0.10 \\
\hline $14 / 15$ & $\begin{array}{c}0.71 \\
(0.45-0.88)\end{array}$ & $\begin{array}{c}0.96 \\
(0.91-0.99)\end{array}$ & $\begin{array}{c}0.71 \\
(0.45-0.88)\end{array}$ & $\begin{array}{c}0.96 \\
(0.91-0.99)\end{array}$ & 18.93 & 0.30 & 63.75 & 0.07 \\
\hline
\end{tabular}


Table 5 - Test characteristics of the BEDS for identification of major depression (DSM-IV)

\begin{tabular}{|c|c|c|c|c|c|c|c|c|}
\hline $\begin{array}{c}\text { Cut- } \\
\text { off }\end{array}$ & $\begin{array}{c}\text { Se } \\
(95 \% \mathrm{Cl})\end{array}$ & $\begin{array}{c}\text { Sp } \\
(95 \% \mathrm{Cl})\end{array}$ & $\begin{array}{c}\text { PPV } \\
(95 \% \mathrm{Cl})\end{array}$ & $\begin{array}{c}\text { NPV } \\
(95 \% \mathrm{Cl})\end{array}$ & PLR & NLR & DOR & OMR \\
\hline $2 / 3$ & $\begin{array}{c}1.00 \\
(0.79-1.0)\end{array}$ & $\begin{array}{c}0.42 \\
(0.33-0.51)\end{array}$ & $\begin{array}{c}0.18 \\
(0.11-0.29)\end{array}$ & $\begin{array}{c}1.00 \\
(0.92-1.0)\end{array}$ & 1.71 & 0 & -- & 0.52 \\
\hline $3 / 4$ & $\begin{array}{c}0.93 \\
(0.69-0.99)\end{array}$ & $\begin{array}{c}0.56 \\
(0.46-0.65)\end{array}$ & $\begin{array}{c}0.22 \\
(0.13-0.34)\end{array}$ & $\begin{array}{c}0.98 \\
(0.91-1.0)\end{array}$ & 2.09 & 0.13 & 16.32 & 0.40 \\
\hline $4 / 5^{a}$ & $\begin{array}{c}0.93 \\
(0.69-0.99)\end{array}$ & $\begin{array}{c}0.66 \\
(0.57-0.74)\end{array}$ & $\begin{array}{c}0.27 \\
(0.16-0.40)\end{array}$ & $\begin{array}{c}0.99 \\
(0.92-1.0)\end{array}$ & 2.73 & 0.11 & 25.28 & 0.31 \\
\hline $5 / 6$ & $\begin{array}{c}0.71 \\
(0.45-0.88)\end{array}$ & $\begin{array}{c}0.76 \\
(0.68-0.84)\end{array}$ & $\begin{array}{c}0.29 \\
(0.16-0.45)\end{array}$ & $\begin{array}{c}0.95 \\
(0.89-0.98)\end{array}$ & 3.03 & 0.37 & 8.10 & 0.24 \\
\hline $6 / 7$ & $\begin{array}{c}0.57 \\
(0.33-0.79)\end{array}$ & $\begin{array}{c}0.88 \\
(0.80-0.93)\end{array}$ & $\begin{array}{c}0.38 \\
(0.21-0.59)\end{array}$ & $\begin{array}{c}0.94 \\
(0.87-0.97)\end{array}$ & 4.66 & 0.49 & 9.54 & 0.16 \\
\hline $7 / 8$ & $\begin{array}{c}0.50 \\
(0.27-0.73)\end{array}$ & $\begin{array}{c}0.92 \\
(0.86-0.96)\end{array}$ & $\begin{array}{c}0.47 \\
(0.25-0.70)\end{array}$ & $\begin{array}{c}0.93 \\
(0.87-0.97)\end{array}$ & 6.63 & 0.54 & 12.25 & 0.13 \\
\hline $8 / 9$ & $\begin{array}{c}0.50 \\
(0.27-0.73)\end{array}$ & $\begin{array}{c}0.95 \\
(0.89-0.98)\end{array}$ & $\begin{array}{c}0.58 \\
(0.32-0.81)\end{array}$ & $\begin{array}{c}0.94 \\
(0.87-0.97)\end{array}$ & 10.60 & 0.52 & 20.20 & 0.10 \\
\hline
\end{tabular}

